Before proceeding to describe these types it is postulated that a rise of temperature, even of half a degree Fahrenheit above the mean, occurring within 72 hours of an injection of tuberculin is to be regarded as a reaction. A rise of temperature reaching its maximum within 24 hours of an injection is an immediate reaction, and may occur four hours after the injection. A rise of temperature reaching its maximum within 48 hours of the injection is a delayed reaction. A rise of temperature reaching its maximum within 72 hours of the injection is a progressive reaction. Now, since all pyrexia must resolve either by crisis or by lysis, it is clear that there may be six types of reaction. This is confirmed by observation.

1. An immediate reaction with a fall by crisis.This, the mildest form of reaction, is due to the tuberculin injected, which is followed by complete immunising response. From the point of dosage it is of least significance, since the dose may be later increased and no reaction occurs.

2. An immediate reaction with a fall by lysis.Here, in addition to the immediate reaction to the tuberculin, there are secondary oscillations due to incomplete immunising response. At the next injection the dose should be reduced by one-fifth the amount-that is to say, from 0.5 c.c. to $0^{\circ} 4$ c.c.

3. A delayed reaction with a fall by crisis.-In this there is delayed absorption of the tuberculin followed by complete immunising response. The : same dose may be repeated at the next injection.

4. A lelayed reaction with a fall by lysis.-Here there is not only delayed absorption of the tuberculin, but an incomplete immunising response. "The amount next injected should be reduced to onehalf of the previous injection-e.g., from 0.79 c.c. to $10^{\circ} 4$ c.c.

5. A progressive reaction with a fall by crisis.-In this there is not only an immediate reaction, but increased toxæmia from a focal reaction, eventually vrercome by immunisation. This is the type of most serious significance, and if not regarded it will be followed by a violent summation temperature or by a gradual and persistent pyrexia, due to prolonged focal reaction. The dose of tuberculin must be reduced to one-tenth at the next injection -from $D_{3} 1$ c.c. to $D_{4} 1$ c.c.

6. A progressive reaction with a fall by lysis.Here a focal reaction is not orercome by immunisation. The disease is lit up in the pulmonary lesion, and may progress by secondary tuberculous bronchopneumonia, of which this temperature is typical. Tuberculin treatment must be stopped, as otherwise the patient will pass into a condition of chronic tuberculous cachexia. The example of this type illustrated in the temperature chart occurred in my practice before one had appreciated the significance of the fifth type as a warning.

In their order of severity these types of temperature reaction are as follows: $a$. Immediate reaction with a fall by crisis-increase dose. $b$. Delayed reaction with a fall by crisis-repeat dose. c. Immediate reaction with a fall by lysis-reduce dose by $\frac{1}{5}$. d. Delayed reaction with a fall by lysisreduce dose by $\frac{1}{2}$. e. Progressive reaction with a fall by crisis-reduce dose to $1 / 10$. $f$. Progressive reaction with a fall by lysis-stop tuberculin.

Results of treatment.-The following are the inmediate results of treating 131 patients, ambulant cases, with polyralent tuberculin on these lines at the St. Marylebone Tuberculosis Dispensary. The record does not include patients who received prophylactic injections. The time of treatment raried from 3 to 25 months. I have used Philip's classi. fication, and a division is made between those whose sputum contained tubercle bacilli and those in whose expectoration the tubercle bacillus was not found. The word "cure" is aroided, but the words "disease arrested" implies that the patient presents neither symptoms nor any signs of active disease.

\begin{tabular}{|c|c|c|c|c|c|c|c|c|c|}
\hline \multirow{2}{*}{-} & & & \multicolumn{3}{|c|}{ T.B. - } & \multicolumn{4}{|c|}{ T.B. +} \\
\hline & & & $\mathbf{L}_{1} \mathbf{s}$ & $\mathrm{L}_{2} \mathrm{~S}$ & $\mathbf{L}_{3} \mathrm{~s}$ & $\mathrm{~L}_{1} \mathrm{~s}$ & $\mathbf{L}_{2} \mathrm{~S}$ & $\mathbf{L}_{3} \mathrm{~s}$ & $\mathrm{~L}_{, 5} \mathrm{~S}$ \\
\hline $\begin{array}{lll}\text { Dead } \ldots & \ldots & \ldots\end{array}$ & $\ldots$ & & - & - & - & - & - & 一 & 1 \\
\hline Worse $\quad \ldots \quad \ldots$ & $\ldots$ & ... & 2 & - & 1 & 1 & 2 & 5 & 5 \\
\hline In statu quo ... & ... & $\ldots$ & 10 & 1 & - & 一 & - & - & 3 \\
\hline Improved $\quad .$. & $\cdots$ & $\ldots$ & 36 & 24 & 4 & 1 & 3 & 8 & 5 \\
\hline Disease arrested & ... & $\ldots$ & 6 & 6 & 5 & - & 1 & 1 & -- \\
\hline Totals ... & ... & $\cdots$ & 54 & 31 & 10 & 2 & 6 & 14 & 14 \\
\hline
\end{tabular}

Allsop-place, W.

\section{TUBAL GESTATION CONTINUING TO THE SIXTH MONTH AFTER RUPTURE AT THE SIXTH WEEK.}

BY ROBER'T NAIRN, F.R.C.S. ENG., L.R.C.P. LoND.

THE following is an account of a condition which is perhaps sufficiently rare to deserve publication in THE LANCET.

The patient, who had been married for six years, had had no children. The cervix was long and narrow, with a small os; the os had been twice dilated. Menstruation had always been painful at first, but it was regular. When seen on Jan. 25th, 1912 , the patient complained that after missing one period menstruation had now gone on for nearly three weeks. Her last period had been on Nov. 24th, 1911. On Jan. 7th, 1912, menstruation began with an unusual amount of pain, especially inside the right hip. There were numerous blood clots. This lasted for about three days; it then stopped, and she felt well till Jan. 11th. She then had violent pains which lasted until the following day, when there was free bleeding for about an hour. It was not pure blood that came away, being very pale, like blood mixed with water. On the 13 th there was a little "blackish" blood passed, and since then there had been a constant discharge of brownish matter.

On examination the breasts were found to be rather full, and they were slightly painful. The uterus was tender and immovable, with thickening all round it, and a brownish purulent discharge from the os. The temperature was $100^{\circ} 4^{\circ} \mathrm{F}$. A diagnosis of miscarriage with subacute parametritis was made. On Jan. 26th the patient was curetted and given hot douches frequently. The curette went in rather to the patient's left. The discharge almost stopped after this, and the temperature remained normal until Feb. 18th, when it rose to over $100^{\circ}$, and the discharge increased, though it was lighter in colour. Hot douching was continued for four weeks longer, after which the temperature remained normal and the discharge stopped entirely. There was still tenderness, with a feeling of thickening about the uterus. On March 21st the patient felt quite well. On examination there were still immobility and matting about the uterus, which had enlarged to the right of the middle line, and a uterine souffle was heard. The breasts had 
distinctly enlarged. An amended diagnosis of either double pregnancy in a bicornuate uterus with miscarriage from the left cornu (normal or ruptured ectopic pregnancy) or fibroid of the uterus with miscarriage was now made. The uterus and breasts continued to enlarge through April and Nay, and the former was nearly up to the umbilicus.

Early in June I again examined the patient and found that the uterus had not continued to rise, and that the souffle was less distinct. Towards the end of June it was evident that the uterus had sunk. There was no souffle and the breasts were smaller.

When again examined on August 3rd a solid mass was felt per vaginam to the patient's right, but matting made it impossible to differentiate the parts. In view of the doubt as to the true condition a laparotomy was decided upon, and this I performed on August 8th, assisted by Dr. W. W. Noore and Dr. MacDonell. On examining the pelvis through the median incision the uterus and left ovary were found to be adherent to the left side. The right broad ligament was obliterated by a large fluctuating swelling in its substance, filling the pelris; and the right ovary and extremity of the Fallopian tube were defined on the surface of this swelling. An incision parallel to the pelvic brim let out a great quantity of dark brown fluid, together with what appeared to be a five-months' foetus with fair-sized placenta.

It was evident that a right tubal pregnancy had ruptured beneath the peritoneum at about the sixth week, and gestation had then progressed until about the sixth month, when it was stopped by want of sufficient blood supply. Convalescence was slow, but eventually the patient recovered perfectly. Hastings, New Zealand.

\section{THE DIAGNOSTIC VALUE OF ABDER- HALDEN'S METHOD IN CARCINOMA.}

\author{
BY R. St. LEGER BROCKMAN, M.R.C.S. ENG., \\ L.R. O.P. LOND., \\ HOUSE SURGEON AT ST. BARTHOLOMEW'S HOSPITAL.
}

Abderhalden, professor of physiology at Halle in Germany, in his work on ferments of the animal system has shown that the body has the power to protect itself against substances which are foreign to it if introduced by subcutaneous or intravenous methods. The injection of cane sugar and vegetable proteids will give the serum of a dog into whose system they are so introduced the power of breaking down these substances into less complex molecules - a faculty wanting in the serm of an animal not so injected.

After Veit had shown that syncytial cells were present in various parts of the body during pregnancy Abderhalden set to work to see if he could show that any attempt was made to defend the body against such invasion, especially as the toxæmias of pregnancy were being attributed to syncytiotoxins. In 1912 he published articles describing the means by which he and his pupils had been able to demonstrate in the blood of a pregnant woman the presence of a substance which has a proteolytic action on placental albumin. He a!so showed that such a substance is absent from the blood of males and non-pregnant women, and further that this ferment is specific, acting on placental tissue only. To do this he made use of two methods-the dialysation method used in the following cases, which will be described later, and the optical method. In this latter case 1 c.c. of a 10 per cent. solution of placental peptone and 2 c.c. of serum from the patient under question are placed in a small polarimeter tube, the initial degree of rotation of light being at once read off. The tube is now placed in an incubator at $37^{\circ} \mathrm{C}$., the tube being removed occasionally and examined by means of a polariscope. Incubation was allowed to proceed up to 36 hours. Abderhalden found that the maximum change of rotation with serum from a case of pregnancy was as high as $0^{\circ} 2^{\circ}$, whilst that when any other serum was used never exceeded $0^{\circ} 03^{\circ}$. His experiments in the case of animals gave similar. results. The practical value of such methods in the diagnosis of pregnancy has been testified to by Abderhalden, Veit, Schwarz, and other observers.

The object of the present paper is to show that a specific ferment is formed against carcinomatous tissue, and to demonstrate the possibility of the existence of such being made use of in the diag. nosis of carcinoma. In all the following cases the dialysation method of Abderhalden has been used.

A piece of coagulated carcinoma tissue, the preparation of which is described later, is placed in a dialysing tube, made from a fish's swim-bladder. To this are added 1.5 c.c. of serum obtained from the patient whose diagnosis is in question. Outside the dialysing tube are 20 c.c. of sterile distilled water. Into a control tube are put 1.5 c.c. of serum alone, from the patient, with 20 c.c. of distilled water outside. The surface of serum and water in both cases is covered with a thin layer of toluol to exclude as far as possible all bacterial contamination. They are now incubated at a temperature of $37^{\circ} \mathrm{C}$. for 12 to 24 hours. At the end of that time 10 c.c. of the diffusiate in each case are added to 0.2 c.c. of a 1 per cent. solution of a reagent known as ninhydrin. (Ninhydrin, or triketohydrindene hydrate, with a formula $\mathrm{C}_{6} \mathrm{H}_{4} \backslash{ }_{\mathrm{CO}}>\mathrm{C}\left(\mathrm{OH}_{2}\right)$, gives a violet colour if

heated with a solution containing minute traces of albumin, peptones, polypeptides, and amino-acids. It gives a reaction with all substances in which the amido group is in $\alpha$ position to carboxyl.) The solution is raised to the boiling point and maintained at that temperature for one minute. If at the end of that time no change takes place in either case the test is negative. If, however, in the case of the one containing carcinomatous tissue a violet colour results whilst the other remains colourless, then a positive result has been recorded. In many cases a brownish tint remains after boiling. This has no connexion with the unmistakable violet colouration of a positive result.

The coagulated cancer tissue was the same for all the following cases. It was obtained from a woman with a large spheroidal-celled carcinoma of the breast. As soon as the breast had been removed by a complete Halstead operation the carcinoma was carefully separated from fat and breast substance. It was then cut up into small pieces which were dropped bit by bit into a beaker of boiling distilled water to which a few drops of glacial acetic acid had previously been added. It was boiled thus for half an hour. The tissue was then washed carefully in distilled water for 12 hours. It was kept ready for use in cold storage in diswater tilled with a layer of toluol on top. Before any was used it had been kept thus for three weeks. The water in which it had been standing was then tested with ninhydrin with a negative result, thus showing that all the albumin had been efficiently coagulated. It was then dialysed with water, saline, and healthy human serum severally. The diffusiate in all cases gave no reaction with ninhydrin. The presence of dialysable products, sufficient to nullify the test, in this cancer tissue was thus excluded. The dialysing tubes were then tested as regaris their permeability to peptones and their impermeability to coll sids. Those which fulfilled these conditions were then used for the tests-all others being rejecte:. In referring to certain pitfalls and sources of 